\title{
Sickrole Compliance and Sickrole Deviance among Tuberculosis Patients on Treatment in Kanyama, a Zambian Shanty Compound
}

\author{
Jason Mwanza \\ Department of Social Development Studies, Sociology Division, University of Zambia, Lusaka, Zambia \\ Email: jasonmwanza2@gmail.com
}

Received 8 December 2015; accepted 14 January 2016; published 19 January 2016

Copyright (C) 2016 by author and Scientific Research Publishing Inc.

This work is licensed under the Creative Commons Attribution International License (CC BY).

http://creativecommons.org/licenses/by/4.0/

(c) (i) Open Access

\begin{abstract}
Background: Kanyama compound has had a DOTS community based programme since 2012 where TB supporters in the community have been fostering the DOTS programme. Prior to this study, research had not been done using Parsonian sickrole behaviour concept to determine the pattern of deviance especially the sickrole behavioural responses on the part of people who were on TB treatment. Methods: This was an exploratory study and the study sample was drawn from a large mixed methods study (quan + QUAL) comprising of 457 men and women $\geq 15$ years. Enrolees were disproportionately sampled using systematic sampling from a population of 1126 men and women who were on multi drug therapy over a two-year period. Categorical and numeric data from the tool was cleaned and analyzed by using SPSS version 21 (Inc., Chicago, USA). Statistical analysis was done using Pearson's Chi square test and ANOVA. A $p$ value of $<0.05$ was considered to be significant. Results: $\mathbf{1 8 . 5 \%}$ of the enrolees honoured medical appointments when due whereas $81.5 \%$ did not. There was a significant association $p<0.05$ with case type and marital status. $39.6 \%$ of the enrolees honoured the medical regimen by taking the prescribed drugs, $33.3 \%$ failed to honour and $27.1 \%$ were not sure. There was a significant association $p<0.05$ between case type and marital status. Conclusions: Strengthening DOTS programs at community level through volunteers to enhance patient adherence to TB treatment and giving personalised attention to men and women who may be at risk of developing secondary tuberculosis, or risk for drug resistance and even dying is recommended. There is evidence to laud the great effort being expended by volunteer community based tuberculosis supporters in ensuring that what DOTS stands for is met.
\end{abstract}

\section{Keywords}

Sickrole, Deviance, Compliance, Adherence, Tuberculosis, Kanyama

How to cite this paper: Mwanza, J. (2016). Sickrole Compliance and Sickrole Deviance among Tuberculosis Patients on Treatment in Kanyama, a Zambian Shanty Compound. Advances in Applied Sociology, 6, 1-11. 


\section{Introduction}

Sociology of health studies like those of Cockehram (2000) on socio-demographic approach, Freidson (1970) on interactional agency theory, Birenbaum (1984) on economic theory, McKinlay (1973) on geographic analysis and Zola (1966) on socio-cultural theory inter alias, have showed that the experience of illness and the role of sick people are both social phenomena. This implies that various kinds of social factors appear to play a fundamental role in shaping patient's subjectivity to the prescription given by health workers. This paper presents results on levels of sickrole behaviour compliance and sickrole deviance which were generated through the application of Parsonian sickrole behaviour concept among people living with tuberculosis in one of the shanty compounds in the City of Lusaka.

Adherence by patients suffering from tuberculosis to the advice and directives of health care providers has been receiving so much since tuberculosis was declared as a global emergency by the World Health Organization as far back as 1993 (WHO, 1994; Grange \& Zumla, 2002). This is largely due to a growing threat to tuberculosis control.

Tuberculosis is still a world-wide public health problem (WHO, 2010) in spite of the fact that there are effective drugs and vaccines to control and prevent the infection (Sarkar \& Suresh, 2011). As far back as 1993, the World Health Organization declared Tuberculosis (TB) was a global health emergency because of the unprecedented mortality, morbidity figures and the emergence of multidrug resistant tuberculosis which was creating an increasing threat to tuberculosis control (WHO, 1994; Grange \& Zumla, 2002). TB was later declared as an emergency in Africa after 46 Ministers of Health unanimously adopted a resolution at the WHO Africa Regional Committee in Maputo, Mozambique, on 25 August 2005. The WHO TB report of 2014 stated that in 2013, an estimated 9.0 million people had developed TB and 1.5 million died from the disease and 360.000 of whom were HIV-positive (WHO, 2014a).

In Zambia, TB has been a public health problem (Mulenga et al., 2010) for more than 40 years after launching the TB/Leprosy National Control Programme (NTP) (Bosman, 2000). In response to this epidemic, Zambia has been delivering DOTS which is a standard short course of drugs lasting up to 6 months for new patients and 9 months for retreatment patients, to individuals diagnosed with TB. This delivery includes the direct observation of therapy (DOT), either by a health worker or by someone nominated by the health worker (in case of the study area, by a volunteer tuberculosis treatment supporter). DOTS is not simply a clinical approach to patients, but rather a management strategy for public health systems. It includes political commitment, case-detection through quality-assured bacteriology, short-course chemotherapy, ensuring patient adherence to treatment, adequate drug supply and sound reporting and recording systems (WHO, 2006).

The prevalence of tuberculosis is high in Kanyama, one of the densely populated compounds which is situated in the heart of the City of Lusaka. Some non-governmental organizations like the Zambia AIDS Related TB (ZAMBART) Project have pioneered, not only in this compound, community based health promotion and treatment support through trained volunteers called TB treatment supporters. These volunteers have been trained in DOTS and are involved in promoting compliance and fostering access to utilization of TB services in the community.

\section{Study Rationale}

Kanyama compound has had a DOTS community based programme since 2012 where TB supporters in the community have been fostering the DOTS programme by helping to improve patient adherence to therapy and completion of treatment. Prior to this study, research had not been done using Parsonian sickrole behaviour concept to determine the pattern of deviance especially the sickrole behavioural responses on the part of people who are on TB treatment. Research elsewhere has shown that noncompliance to the DOTS regimen, which is an abrogation of the sickrole behaviour, leads to treatment failure, relapse, and extensively drug resistant tuberculosis (Khan et al., 2001; Sharma \& Mohan, 2004; Zai et al., 2010; Srivastava et al., 2011; WHO, 2014b). Hence, the aim of the present study was to profile the level and pattern of patient behaviour in terms of compliance as well as non-compliance with the doctor's orders of adherence to the sickrole behaviour (fulfilling customary obligations that surround TB as a disease) inter alias taking prescribed medication doses at prescribed intervals, keeping medical appointments and following advice related to behaviours other than medication taking, such as diet restrictions and exercise (Cramer, 1991; O’Brien et al., 1992; Besch, 1995; Volmink et al., 2000). 


\section{Theoretical Frame for the Construction of Sickrole Practices}

Talcott Parsons' sickrole theory provides the heuristics for this study. Parsons is the progenitor of the concept sick role, a term which refers to the notion that our repertoire of responses to illness is governed by a set of social expectations and responsibilities (Parsons, 1951). Talcott Parsons' sickrole theory posits that a sick person ought to cooperate with a physician who is an authority figure in society and the sick person should try to get well (Parsons, 1951: pp. 339-440; 1972: pp. 107-108; Fox, 1989: p. 17) for a given duration (Jones, 1991; Cockerham, 2000). This cooperation is from a sick person and trying to get well only for a given period, demands from a sick person the duty to perform the prescribed sick role behaviours. In essence, it is incumbent upon the sick person to honour the doctor's orders or the prescription such as keeping medical appointments and following advice related to behaviours other than medication taking, such as diet (Cramer, 1991; O’Brien et al., 1992; Besch, 1995; Volmink et al., 2000). These are some of normative customary obligations that surround illness in a society (Cockerham, 2001; Bissell et al., 2002).

\section{Material and Methods}

This study was conducted from May 2011 to April 2013 in Kanyama compound in Zambia. Medical services are centered at Kanyama Health Centre, where a tuberculosis DOTS program has been in operation for some time. The study sample was drawn from a large mixed methods study (quan + QUAL) comprising of 457 men and women $\geq 15$ years. Enrolees were disproportionately sampled using systematic sampling from a population of 1,126 men and women who were on Multi Drug Therapy from May 2011 to April 2013. TB supporters community based DOTS surveillance registers were used as sampling frames. The study protocol was approved by a local research ethics committee. To be enrolled in the study, enrolees ought to have been i) active pulmonary TB patients on treatment for more than two weeks ii) appearing on the TB treatment supporter's register and ought to have been followed while on the treatment course. Willingness to participate in the study was also an inclusion criterion. The main variables of interest in this study were sickrole behaviour which was dichotomised and operationalised as follows:

a) Compliance with the sickrole behaviour being actions which are demonstrable in person who is living with tuberculosis and follows a health worker's prescription including a) honouring appointments to be reviewed when scheduled and $b$ ) taking drugs as scheduled.

b) Deviant sickrole behaviour being actions which are demonstrable in a person who is living with tuberculosis and does not follow a health worker's prescription. This non-compliance is demonstrable in person who is living with tuberculosis in form of i) failure to take any medication, ii) discontinuation of treatment prematurely or iii) deviation from the prescribed treatment including brief treatment interruptions and dishonouring review appointments when scheduled.

Other variables included sex, education, marital status, treatment phase, case type and smear status.

Data was collected from the homes of enlisted respondents. All potential respondents were presented with a research pack, which contained a) the information sheet, b) consent form and c) the Modified Explanatory Model Interview Catalogue (EMIC). The EMIC was a data collection tool that is used in cultural anthropology to elicit gender illness-related experience. It was originally designed by WHO/TDR Collaborative Research Study. The tool that was modified was based on the on the February $2^{\text {nd }} 2010$ version revised from the master copy with categories for all sites. Data was collected from enrolees with the help of respective TB supporters who monitored patients' DOTS sickrole behaviour. Categorical and numeric data from the tool was cleaned and analyzed by using SPSS version 21 (Inc., Chicago, USA). Statistical analysis was done using Pearson's Chi square test and ANOVA. A $p$ value of $<0.05$ was considered to be significant.

\section{Results}

\subsection{Demographic Profile}

The sample was rather a youthful. The youngest was 18 whereas the oldest was 69 and the sample $\mu$ age was $35.5(\mathrm{SD} \pm 4.3)$. Out of the 457 enrolees, there were slightly more females $n=231(50.5 \%)$ as compared to $n=$ 226 (49.5\%) males. A diverse range of levels of education and income generating backgrounds was observed. Two hundred and eighteen $(47.7 \%)$ had attended primary school, $n=177$ (38.7\%) attended secondary education and $n=62$ (13.65) had never been to school. The mean schooling years was 7 ( $\mathrm{SD} \pm 3.6)$. The sample's literacy 
rate was $38.7 \%$ and this was lower than the nation's rate which was $61.4 \%$ at the time of the study. As expected, men had a better education completion rate high school 58.2\% than women $41.8 \% ; p=0.005$ ). More than half of enrolees in the sample $n=299$ (65.4\%) had no definite means of earning a living and $n=158$ had a definite means of earning a living. Those who had some means of earning a living did so by trading, doing clerical jobs, doing casual jobs and being house boys/maids. There was however, no association between sex of enrolee and type of occupation $p=0.247$. Just over half $n=257$ (56.2\%) enrolees were married and $n=200$ (43.8\%) were single, widowed or divorced. There was however a significant association between sex of enrolee and type of occupation $p=0.016$ (Table 1 ).

\subsection{Clinical Profile of Patients}

Just over half $n=258$ (56.4\%) had a smear positive sputum and $n=199$ (43.6\%) had a smear negative sputum. There was no significant association between the sex of enrolees and their smear status $(p>0.625)$ (Table 1). More primary cases of tuberculosis were enrolled in the study $n=358(78.3 \%)$ as compared to $n=99(21.7 \%)$ relapse cases. There was however, no significant association between the sex of enrolees and case type $(p=$ 0.170) (Table 1). Just over half of the enrolees $n=243$ (53.2\%) were in the intensive phase of their treatment which stage is designed for rapid killing of actively growing bacilli and of semi-dormant bacilli whereas just below half $n=214$ (46.8\%) where in their continuation phase of their treatment. However, there was no significant association between the sex of enrolees and treatment phase $(p=0.179)$ (Table 2).

The $\mu$ duration of treatment in the intensive phase was 6 weeks ( $\pm 2 \mathrm{SD}$ ) whereas in the continuation phase, the $\mu$ was 4 weeks ( \pm 5 SD). The $\mu$ total duration (those who had an experience with both phases) was 10 weeks $( \pm 7 \mathrm{SD}$ ). In spite of this distribution, the sex of the enrolee was not a factor in terms of phase of treatment since $p$ was $>0.05$. In essence, it is very likely men and women take the same duration of treatment in the two phases (Table 3).

\subsection{Sickrole Compliance and Sickrole Deviance}

When sickrole behaviour compliance and deviant sickrole behaviour were assessed in terms of a) honouring or dishonouring medical clinic reviews when scheduled and b) honouring or dishonouring medical regimens, there

Table 1. Demographic profile of patients and values of associations.

\begin{tabular}{|c|c|c|c|c|c|c|c|}
\hline & & & & & \multicolumn{3}{|c|}{ Significance } \\
\hline & \multicolumn{2}{|c|}{ Male $N=226(49.5 \%)$} & \multicolumn{2}{|c|}{ Female $N=231(50.5 \%)$} & $\chi^{2}$ & $d f$ & $P$ value \\
\hline Education & $f$ & $\%$ & $f$ & $\%$ & & & \\
\hline Never been to school & 32 & 51.6 & 30 & 48.4 & & & \\
\hline Primary & 91 & 41.7 & 127 & 58.3 & 10.707 & 2 & 0.005 \\
\hline Secondary & 103 & 58.2 & 74 & 41.8 & & & \\
\hline \multicolumn{8}{|l|}{ Occupation } \\
\hline Trader/business & 31 & 50.8 & 30 & 49.2 & & & \\
\hline Sales/clerical job & 11 & 47.8 & 12 & 52.2 & & & \\
\hline Nothing & 137 & 48.2 & 147 & 51.8 & 5.414 & 4 & 0.247 \\
\hline Casual jobs & 37 & 60.7 & 24 & 39.3 & & & \\
\hline House boy/maid & 10 & 35.7 & 18 & 64.3 & & & \\
\hline \multicolumn{8}{|l|}{ Marital Status } \\
\hline Married & 133 & 51.8 & 124 & 48.2 & & & \\
\hline Single & 63 & 54.8 & 52 & 45.2 & 10.323 & 3 & 0.016 \\
\hline Widowed & 14 & 29.2 & 34 & 70.8 & & & \\
\hline Divorced & 16 & 43.2 & 21 & 56.8 & & & \\
\hline
\end{tabular}


Table 2. Clinical profile of patients and values of associations.

\begin{tabular}{|c|c|c|c|c|c|c|c|}
\hline & \multicolumn{4}{|c|}{ Smear Type } & \multicolumn{3}{|c|}{ Significance } \\
\hline & \multicolumn{2}{|c|}{ Males $N=199(43.6 \%)$} & \multicolumn{2}{|c|}{ Females $N=258(56.4 \%)$} & \multirow[t]{2}{*}{$\chi^{2}$} & \multirow[t]{2}{*}{$d f$} & \multirow[t]{2}{*}{$P$ value } \\
\hline Sex & $f$ & $\%$ & $f$ & $\%$ & & & \\
\hline Positive & 101 & 50.7 & 125 & 48.4 & \multirow[t]{2}{*}{-} & \multirow[t]{2}{*}{-} & \multirow[t]{2}{*}{-} \\
\hline Negative & 98 & 49.3 & 133 & 51.6 & & & \\
\hline \multicolumn{5}{|c|}{ Case type } & \multicolumn{3}{|c|}{ Significance } \\
\hline & \multicolumn{2}{|c|}{ New Cases $N=358(78.3 \%)$} & \multicolumn{2}{|c|}{ Retreatments $N=99$ (21.7\%) } & $\chi^{2}$ & $d f$ & P value \\
\hline Sex & $f$ & $\%$ & $f$ & $\%$ & & & \\
\hline Male & 171 & 47.7 & 55 & 55.9 & 1.883 & 1 & 0.170 \\
\hline Female & 187 & 52.3 & 44 & 44.1 & & & \\
\hline \multicolumn{5}{|c|}{ Treatment phase of case type } & \multicolumn{3}{|c|}{ Significance } \\
\hline & \multicolumn{2}{|c|}{ Continuation Phase $N=214$} & \multicolumn{2}{|c|}{ Intensive Phase $N=243$} & $\chi^{2}$ & $d f$ & P value \\
\hline Sex & $f$ & $\%$ & $f$ & $\%$ & & & \\
\hline Male & 113 & 52.8 & 113 & 46.5 & 1.808 & 1 & 0.179 \\
\hline Female & 101 & 47.2 & 130 & 54.5 & & & \\
\hline
\end{tabular}

Table 3. ANOVA Sample Statistics of Duration of Therapy by Phase.

\begin{tabular}{|c|c|c|c|c|}
\hline & & $d f$ & $\boldsymbol{F}$ & Sig. \\
\hline \multirow{3}{*}{$\begin{array}{l}\text { On treatment intensive phase } \\
\text { in weeks }\end{array}$} & Between Groups & 1 & 2.90 & 0.089 \\
\hline & Within Groups & 455 & - & - \\
\hline & Total & 456 & - & - \\
\hline \multirow{3}{*}{$\begin{array}{l}\text { On treatment continuation } \\
\text { phase in weeks }\end{array}$} & Between Groups & 1 & 2.13 & 0.145 \\
\hline & Within Groups & 455 & - & - \\
\hline & Total & 456 & - & - \\
\hline \multirow{3}{*}{ Total duration of treatment } & Between Groups & 1 & 2.74 & 0.098 \\
\hline & Within Groups & 455 & - & - \\
\hline & Total & 456 & - & - \\
\hline
\end{tabular}

were variations in sickrole behaviours in this simple.

\subsubsection{Honouring Appointments}

Out of 457 enrollees, $n=84$ (18.4\%) honoured appointments when due whereas $n=373$ (81.6\%) did not honour their appointments for medical review. Sickrole deviance in terms of honouring medical reviews in the six demographic categories was in excess of $73 \%$. There were more instances of sickrole deviance (dishonouring medical reviews when scheduled) than sickrole compliance (honouring appointments to be reviewed when scheduled) in all of the six demographic categories (Table 4). There were significant associations noted with sex, marital status, case type and level of education and dishonouring medical reviews. In both instances, the $p$ values where $<0.05$. Smear status, treatment phase and marital status of enrollees in turn showed no association because the $p$ vales where $>0.05$ (Table 4 ).

\subsubsection{Honouring Medical Regimen}

Out of 457 enrolees, $\mathrm{n}=181$ (39.6\%) honoured the medical regimen by taking the prescribed drugs, $\mathrm{n}=152$ (33.3\%) did not and $n=124$ (27.1\%) were not sure and claimed they possibly did honour the medical regimen 
Table 4. Levels of sickrole compliance and sickrole deviance for medical review demographics.

\begin{tabular}{|c|c|c|c|c|c|c|c|}
\hline \multirow[t]{2}{*}{ Demographic variable } & \multicolumn{2}{|c|}{$\begin{array}{l}\text { Did not perform the sickrole behaviour- } \\
\text { dishonouring review } N=372(81.4 \%)\end{array}$} & \multicolumn{2}{|c|}{$\begin{array}{l}\text { Performed The sickrole behaviour- } \\
\text { honouring review } N=85 \text { (18.6\%) }\end{array}$} & \multicolumn{3}{|c|}{ Significance } \\
\hline & $f$ & $\%$ & $f$ & $\%$ & $\chi^{2}$ & $d f$ & $p$ value \\
\hline \multicolumn{8}{|l|}{ Sex } \\
\hline Male & 174 & 77.0 & 52 & 23.0 & 6.834 & 1 & 0.012 \\
\hline Female & 199 & 86.1 & 32 & 13.9 & & & \\
\hline \multicolumn{8}{|l|}{ Marital Status } \\
\hline Married & 199 & 77.4 & 58 & 22.6 & & & \\
\hline Single & 99 & 86.1 & 16 & 13.9 & 7.598 & 3 & 0.055 \\
\hline Widowed & 41 & 85.4 & 7 & 14.6 & & & \\
\hline Divorced & 34 & 91.9 & 3 & 8.1 & & & \\
\hline \multicolumn{8}{|l|}{ Case type } \\
\hline New case & 281 & 78.5 & 77 & 21.5 & 10.776 & 1 & 0.001 \\
\hline Relapse & 92 & 92.9 & 7 & 7.1 & & & \\
\hline \multicolumn{8}{|l|}{ Treatment phase } \\
\hline Continuation & 175 & 81.8 & 39 & 18.2 & 0.007 & 1 & 0.935 \\
\hline Intensive & 198 & 81.5 & 45 & 18.5 & & & \\
\hline \multicolumn{8}{|l|}{ Smear status } \\
\hline Negative & 163 & 81.9 & 36 & 18.1 & 0.020 & 1 & 0.888 \\
\hline Positive & 210 & 81.4 & 48 & 18.6 & & & \\
\hline \multicolumn{8}{|l|}{ Education } \\
\hline Never & 55 & 88.7 & 7 & 11.3 & & & \\
\hline Primary & 188 & 86.2 & 30 & 13.8 & 13.059 & 2 & 0.001 \\
\hline Secondary & 130 & 73.4 & 47 & 26.6 & & & \\
\hline
\end{tabular}

(Table 5). Nonetheless, the first two are collectively considered as deviance. There were more instances of sickrole deviance (dishonouring the medical regimen) than sickrole compliance in all demographic categories. Sickrole deviance in the demographic categories was generally in excess of $60 \%$. In terms of patterns related to the medical regimen, there were significant associations noted with case type and marital status because the $p$ values in the two demographic categories where $<0.05$. Sex, treatment phase, smear status and education of enrollees in turn showed no association because the $p$ vales where $>0.05$ (Table 5).

\section{Discussion}

This study assessed on one hand sickrole behaviour compliance and sickrole deviance based on Talcott Parson's concept of sickrole behaviour. Though this study asked enrolees to report an incidence of deviance during the course of treatment, the study has established a sickrole compliance rate of $39.6 \%$ honouring the medical regimen, a sickrole deviant rate of $33.3 \%$ and $27.1 \%$ of possible deviance - those unsure. These incidence rates point to the fact that the set of defined roles, norms and expectations of people who were living with tuberculosis where widely breeched. Patients on TB treatment are bound to miss appointments which are mandatory to assess their prognosis. They are as well likely to fail to collect drugs when the appointment coincides with drug refills. In addition, one is likely to infer that interruptions or missing doses as well as sub optimal and overdosing though could have been of very short durations, are likely to inhibit the capacity to achieve or maintain a therapeutic drug level necessary to effectively treat TB. The study further demonstrates that the patterns of deviance across the demographic variables are not consistent in the two types of sickrole behaviours. Case type was the only demographic variable that demonstrated a significantly association with the two types of sickrole 
Table 5. Levels of sickrole compliance and sickrole deviance for medical regimen by demographics.

\begin{tabular}{|c|c|c|c|c|c|c|c|c|c|}
\hline \multirow[t]{2}{*}{$\begin{array}{c}\text { Demographic } \\
\text { variable }\end{array}$} & \multicolumn{2}{|c|}{$\begin{array}{l}\text { Honoured the medical } \\
\text { regimen } N=181 \\
(39.6 \%)\end{array}$} & \multicolumn{2}{|c|}{$\begin{array}{l}\text { Did not honour the } \\
\text { medical regimen } N \\
\quad=152(33.3 \%)\end{array}$} & \multicolumn{2}{|c|}{$\begin{array}{c}\text { Possibly honoured the } \\
\text { medical regimen } N= \\
124(27.1 \%)\end{array}$} & \multicolumn{3}{|c|}{ Significance } \\
\hline & $f$ & $\%$ & $f$ & $\%$ & $f$ & $\%$ & $\chi^{2}$ & $d f$ & $p$ value \\
\hline \multicolumn{10}{|l|}{ Sex } \\
\hline Male & 89 & 39.4 & 77 & 34.1 & 60 & 26.5 & 0.150 & 2 & 0.928 \\
\hline Female & 92 & 39.8 & 75 & 32.5 & 64 & 27.7 & & & \\
\hline \multicolumn{10}{|l|}{ Marital Status } \\
\hline Married & 84 & 32.7 & 95 & 37.0 & 78 & 30.4 & 18.684 & 6 & 0.005 \\
\hline Single & 49 & 42.6 & 41 & 35.7 & 25 & 21.7 & & & \\
\hline Widowed & 28 & $58.3^{*}$ & 9 & 18.8 & 11 & 22.9 & & & \\
\hline Divorced & 20 & 54.1 & 7 & 18.9 & 10 & 27.0 & & & \\
\hline \multicolumn{10}{|l|}{ Case type } \\
\hline New case & 104 & 29.1 & 142 & 39.7 & 112 & 31.3 & 77.369 & 2 & 0.001 \\
\hline Relapse & 77 & $77.8^{*}$ & 10 & 10.1 & 12 & 12.1 & & & \\
\hline \multicolumn{10}{|l|}{$\begin{array}{l}\text { Treatment } \\
\text { phase }\end{array}$} \\
\hline Continuation & 82 & 38.3 & 70 & 32.7 & 62 & 29.0 & 0.707 & 2 & 0.702 \\
\hline Intensive & 99 & 40.7 & 82 & 33.7 & 62 & 25.5 & & & \\
\hline \multicolumn{10}{|l|}{ Smear status } \\
\hline negative & 90 & 45.2 & 59 & 29.6 & 50 & 25.1 & 4.718 & 2 & 0.095 \\
\hline Positive & 91 & 35.3 & 93 & 36.0 & 74 & 28.7 & & & \\
\hline \multicolumn{10}{|l|}{ Education } \\
\hline Never & 29 & 46.8 & 19 & 30.6 & 14 & 22.6 & 6.045 & 4 & 0.196 \\
\hline Primary & 74 & 33.9 & 77 & 35.3 & 67 & 30.7 & & & \\
\hline Secondary & 78 & 44.1 & 56 & 31.6 & 43 & 24.3 & & & \\
\hline
\end{tabular}

deviant behaviours (conforming to the expectations of medical reviews and medical regimen) (see Table 6). In either cases, the $p$ values were $<0.05$ ( 0.001 for medical regimen and 0.002 for medical review) as shown by the asterisk mark on case type.

The low rates of expected sickrole affirm one of the notable problems with health related behaviours. Patients ought to adhere to the prescriptions of the tuberculosis sickrole behaviour if they are to achieve the success of treatment including the accentuating the probability of cure, decreasing the risk of relapse and minimizing drug resistance (Maartens \& Wilkinson, 2007; Trajman et al., 2010). It was not expected to see a high incidence of expected sickrole behaviour regarding compliance to medication among relapses $(77.8 \%)$ than among new cases (29.1\%) being an enrolee who has never had treatment for tuberculosis, or who has taken TB drugs for less than 1 month. It was expected to see widows (83.3\%) being more deviant than those who were married (77.4\%). It was not expected to see those who had relapses $(91.9 \%)$ to have higher incidences of deviance regarding medical reviews than new cases (78.5\%). We can hypothesize that compliance to the expected tuberculosis sickrole behaviour may be explained using the cues variable within the health belief model. There could be numerous factors which may have triggered compliance within this sub population. These may be explained by testing illness and health behaviour theories or by qualitatively eliciting the lived experiences.

\subsection{Limitations and Significances of the Study}

All research has design and methodological limitations and this study is not exempted from such. The first limi- 
Table 6. Levels of sickrole compliance and sickrole deviance for medical review by demographics.

\begin{tabular}{|c|c|c|c|c|c|c|}
\hline \multirow{2}{*}{ Demographic variable } & \multicolumn{3}{|c|}{ Significance medical regimen } & \multicolumn{3}{|c|}{ Significance medical review } \\
\hline & $\chi^{2}$ & $d f$ & $p$ value & $\chi^{2}$ & $d f$ & $p$ value \\
\hline \multicolumn{7}{|l|}{ Sex } \\
\hline Male & 0.150 & 2 & 0.928 & 5.741 & 1 & 0.0171 \\
\hline \multicolumn{7}{|l|}{ Female } \\
\hline \multicolumn{7}{|l|}{ Marital Status $^{*}$} \\
\hline \multicolumn{7}{|l|}{ Married } \\
\hline Single & 18.684 & 6 & 0.005 & 7.598 & 3 & 0.055 \\
\hline \multicolumn{7}{|l|}{ Widowed } \\
\hline \multicolumn{7}{|l|}{ Divorced } \\
\hline \multicolumn{7}{|l|}{ Case type ${ }^{*}$} \\
\hline New case & 77.369 & 2 & 0.001 & 9.23 & 1 & 0.002 \\
\hline \multicolumn{7}{|l|}{ Relapse } \\
\hline \multicolumn{7}{|l|}{ Treatment phase } \\
\hline Continuation & 0.707 & 2 & 0.702 & 0.03 & 1 & 0.847 \\
\hline \multicolumn{7}{|l|}{ Intensive } \\
\hline \multicolumn{7}{|l|}{ Smear status } \\
\hline Negative & 4.718 & 2 & 0.095 & 0.00 & 1 & 0.997 \\
\hline \multicolumn{7}{|l|}{ Positive } \\
\hline \multicolumn{7}{|l|}{ Education } \\
\hline \multicolumn{7}{|l|}{ Never } \\
\hline Primary & 6.045 & 4 & 0.196 & 12.346 & 2 & 0.002 \\
\hline Secondary & & & & & & \\
\hline
\end{tabular}

tation is associated with the operational definition of deviant sickrole behaviour and the researcher's quest to measure incidence of sickrole behaviour and deviant sickrole behaviour. As such, these survey findings need to be interpreted with caution, and read with awareness that this was not an adherence and compliance study. The definition of deviant sickrole behaviour particularly relating non-compliance (failure to take any medication, (ii) discontinuation of treatment prematurely or (iii) deviation from the prescribed treatment including brief treatment interruptions) did not provide room to include the normative compliance measures in a DOTS programme. This is because drug adherence, compliance and drug interruptions were assessed as an instance of deviance and not deviant behaviours over time. The operationalization of deviant sickrole behaviour could have embraced a) missing $>$ or $=2$ consecutive weeks of DOT and prolongation of treatment for $>30$ days due to sporadic missed doses and b) the normative compliance measures of defaulting which include a patient whose treatment was interrupted for two or more consecutive months for any reason without medical approval (Burman et al., 1997; Ansari et al., 2013) after at least one month on treatment (WHO, 2008). Therefore, from this study, it is not possible to make any conclusions on TB compliance and defaulting. The only conclusions that could be drawn from this study are about incidence of compliance and deviation from the TB sickrole behaviour. While this may be the case, this measurement of incidence of deviance is not from a public health or clinical perspective but from sociology of health and illness perspective.

The second limitation is associated with recall bias. The EMIC provides respondents a response like "Possibly”. Recognizing that the recall of information depends entirely on memory which can often be imperfect among people with tuberculosis which is a chronic illness renders their responses rather unreliable. However, in spite of this limitation, the findings have some validity because they are based on reporting an incidence of de- 
viance and the risk of recall bias is not high in incidence studies. The third limitation is that this study was conducted in one setting in the City of Lusaka and therefore these results may not be generalisable to the rest of the City.

In spite of these limitations, this study is significant in that it has examined compliance to a medical prescription from a Parsonian sociological perspective by quantifying the incidences and patterns of deviance as a potential social and public health problem. The data that has emerged from this study adds to the existing pool of knowledge on deviance and sociology of health and illness. The study has further affirmed that Talcott Parson's sick role theory particularly the duty to cooperate with a physician who is an authority figure in society and the sick person trying to get well (Parsons, 1978; Fox, 1989) and for a given duration, is valid not only in acute stages of tuberculosis but could be extended to sub-acute as well as chronic stages of the illness.

\subsection{Conclusions and Recommendations}

Based on the results, it is evident that Parson's sickrole behaviour has additional analytic value in chronic illnesses like tuberculosis. The observed incidence rates of sickrole behaviour deviance remain a sensitizing and an organizing concept to monitor the DOTS programme and conduct the future research. Given the limitations of the study, there is a need to include within the EMIC, precise measurements of compliance. The EMIC could embrace the World Health Organization maxims of adherence and compliance. There is a need to conduct adherence and compliance studies in Kanyama Compound in order to determine if the compliance rate is lower or higher than the World Health Organization threshold of 5\%.

It is recommended that tuberculosis supporters re-emphasize to their clientele the core knowledge of anti-TB treatment regimen and the importance of medical reviews. Since there could be numerous factors which may have triggered compliance within this sub population, it would be necessary in the future to test the assumptions of the illness and health behaviour theories.

There is an urgent need for early and continuous motivation in health education and counselling of patients on DOTS adherence and compliance. The community based social services which could reach patients at their doorsteps through TB supporter programmes like those in Kanyama Compound ought to be sustained since they have shown to be an integral part of the patient-oriented DOTS program. One way of sustaining the community based DOTS program is to consider developing an essential package of incentives for TB treatment supporters. The Global Fund and the Zambia National TB Programme could facilitate the development and funding of such an essential package. Last, but not the least, there is a need for a continued campaign to educate the masses using electronic and print media regarding the need for fulfilling the expected sickrole behaviours.

\section{Acknowledgements}

I would like to acknowledge the respondents for their valuable contributions. My particular thanks go to the tuberculosis supporters for being available to walk with me in the field to reach out to the respondents.

\section{Funding}

This work was supported by funding for doctoral research from the University of Zambia.

\section{Declaration of Interest}

The views expressed are not necessarily those of the funder. The author alone is responsible for the content and writing of the paper.

\section{Author Biography}

Jason Mwanza is a lecturer in Sociology at the University of Zambia. His research areas revolve around sociology of health, gender, mental health and mental health policy and has publications with other authors in Global Health Promotion, Medical Journal of Zambia, Bangladesh e-Journal of Sociology, Global Health Promotion, International Review of Psychiatry, African journal of Psychiatry, Health Research Policy and Systems, International Journal of Mental Health Systems, Health Policy and Planning and International Journal of Culture and Mental Health. 


\section{References}

Ansari, M. S., Khayyam, K. U., Sharma, M., \& Alam, S. (2013). The Contribution of Disease and Drug Related Factors to Non-Compliance with Directly Observed Treatment Short Course Among Tuberculosis Patients. African Journal of Pharmacy and Pharmacology, 7, 2466-2473. http://dx.doi.org/10.5897/AJPP12.1263

Besch, C. L. (1995). Compliance in Clinical Trials. AIDS, 9, 1-10. http://dx.doi.org/10.1097/00002030-199501000-00001

Birenbaum, A. (1984). Health Care and Society. New Jersey: Allanheld and Osmun.

Bissell, P., Trausen, M. J., \& Haugbølle, L. S. (2002). Sociological Theory and Pharmacy Practice Research. An Introduction to Functionalist Sociology: Talcott Parsons' Concept of the Sickrole. International Journal of Pharmacy Practice, 10, 6068. http://dx.doi.org/10.1111/j.2042-7174.2002.tb00589.x

Bosman, M. C. (2000). Health Sector Reform and Tuberculosis Control: The Case of Zambia. The International Journal of Tuberculosis and Lung Disease, 4, 606-614.

Burman, W. J., Cohn, D. L., Rietmeijer, C. L., Judson, F. N., Sbarbaro, J. A., \& Reves, R. R. (1997). Noncompliance with Directly Observed Therapy for Tuberculosis. Epidemiology and Effect on the Outcome of Treatment. Chest, 111, 11681173. http://dx.doi.org/10.1378/chest.111.5.1168

Cockerham, W. (2000). Medical Sociology. Upper Saddle River, NJ: Prentice-Hall.

Cockerham, W. C. (2001). Medical Sociology and Sociological Theory. In W.C. Cockerham (Ed.), The Blackwell Companion to Medical Sociology (pp. 3-22). Malden, MA: Blackwell Publishing. http://dx.doi.org/10.1002/9780470996447.ch1

Cramer, J. (1991). Overview of Methods to Measure and Enhance Patient Compliance. In J. Cramer \& B. Spiker (Eds.), Patient Compliance in Medical Practice and Clinical Trials (pp. 3-10). New York: Raven Press.

Fox, R. (1989). The Sociology of Medicine: A Participant Observer’s View. Englewood.

Freidson, F. (1970). Profession of Medicine. New York: Harper and Row.

Grange, J. M., \& Zumla, A. (2002). The Global Emergency of Tuberculosis: What Is the Cause? The Journal of the Royal Society for the Promotion of Health, 122, 78-81. http://dx.doi.org/10.1177/146642400212200206

Jones, R. K. (1991). Sociology of Health and Illness. Kenwyn: Juta and Co. Ltd.

Khan, K., Pillay, T., Moodley, J. M., \& Connolly, C. C. (2001). Maternal Mortality Associated with Tuberculosis-HIV-1 Co-Infection in Durban, South Africa. AIDS, 15, 1857-1863. http://dx.doi.org/10.1097/00002030-200109280-00016

Maartens, G., \& Wilkinson, R. J. (2007). Tuberculosis. The Lancet, 370, 2030-2043. http://dx.doi.org/10.1016/S0140-6736(07)61262-8

McKinlay, J. (1973). Social Networks, Lay Consultation and Help-Seeking Behaviour. Social Forces, 51, $275-279$. http://dx.doi.org/10.1093/sf/51.3.275

Mulenga, C., Shamputa, I. C., Mwakazanga, D., Kapata, N., Portaels, F., \& Rigouts, R. (2010). Diversity of Mycobacterium Tuberculosis Genotypes Circulating in Ndola, Zambia. BMC Infectious Diseases, 10, 177.

http://www.biomedcentral.com/1471-2334/10/177 http://dx.doi.org/10.1186/1471-2334-10-177

O’Brien, M. K., Petrie, K., \& Raeburn, J. (1992). Adherence to Medication Regimens: Updating a Complex Medical Issue. Medical Care Research and Review, 49, 435-454. http://dx.doi.org/10.1177/002570879204900403

Parsons, T. (1951). The Social System. Glencoe, IL: The Free Press.

Parsons, T. (1978). Action Theory and the Human Condition. New York: Free Press.

Sarkar, S., \& Suresh, M. R. (2011). An Overview of Tuberculosis Chemotherapy-A Literature Review. Journal of Pharmacy and Pharmaceutical Science, 14, 148-161.

Sharma, S. K., \& Mohan, A. (2004). Multidrug-Resistant Tuberculosis. Indian Journal of Medical Research, 120, 354-376.

Srivastava, S., Pasipanodya, J. G., Meek, C., Leff, R., \& Gumbo, T. T. (2011). Multidrug-Resistant Tuberculosis Not Due to Noncompliance but to Between-Patient Pharmacokinetic Variability. The Journal of Infectious Diseases, 204, $1951-1959$. http://dx.doi.org/10.1093/infdis/jir658

Trajman, A., Long, R., Zylberberg, D., Dion, M. J., Al-Otaibi, B., \& Menzies, D. (2010). Factors Associated with Treatment Adherence in a Randomised Trial of Latent Tuberculosis Infection Treatment. The International Journal of Tuberculosis and Lung Disease, 14, 551-559.

Volmink, J., Matchaba, P., \& Garner, P. (2000). Directly Observed Therapy and Treatment Adherence. The Lancet, 355, 1345-1350. http://dx.doi.org/10.1016/S0140-6736(00)02124-3

WHO (1994). WHO Report on the TB Epidemic. (WHO/TB/94.177), Geneva: World Health Organisation.

WHO (2006). World Health Organization. The Global Plan to Stop TB. 2006-2015: PART I Strategic Directions.

http://www.stoptb.org/assets/documents/global/plan/globalplanfinal.pdf 
WHO (2008). World Health Organization Guidelines for the Programmatic Management of Drug-Resistant Tuberculosis. Geneva: World Health Organisation.

WHO (2010). Global Tuberculosis Control: WHO Report 2010. Geneva: World Health Organisation.

WHO (2014a). Antimicrobial Resistance: Global Report on Surveillance. Geneva: World Health Organisation.

WHO (2014b). Tuberculosis Control: The Situation in the African Region. 55th Session of the WHO Regional Committee for Africa, Maputo, 22-26 August 2005, AFR/RC55/20. Brazzaville: World Health Organization Regional Office for Africa; 2005.

http://www.afro.who.int/en/downloads/doc_download/1597-fifty-fifthsession-of-the-who-regional-committee-for-africa-fi nal-report.html

Zai, S., Haroon, T., \& Mehmood, K. T. (2010). Socioeconomic Factors Contributing to Multidrug-Resistant Tuberculosis (MDR-TB). Journal of Biomedical Science and Research, 2, 279-283.

Zola, I. K. (1966). Culture and Symptoms: An Analysis of Patients Presenting Complaints. American Sociological Review, 31, 615-630. http://dx.doi.org/10.2307/2091854 